\title{
The Influence of Rib Configuration on Bond Strength Development between Steel and Concrete
}

\author{
Shoib Bashir Wani ${ }^{1, *}$, Dar Sarvat Gull2, Ishfaq Amin ${ }^{3}$ \\ ${ }^{1}$ Department of Civil Engineering, B. S. Abdur Rahman University Vandalur, INDIA \\ Chennai, India. PIN-600048 \\ ${ }^{2}$ Department of Civil Engineering, National Institute of Technology Srinagar, INDIA \\ Jammu \& Kashmir, India. PIN-190006 \\ ${ }^{3}$ Department of Civil Engineering, Maharshi Dayanand University Rothak, INDIA \\ Haryana, India. PIN-124001 \\ *Corresponding authors: shoibbwani@gmail.com
}

SUBMITTED 30 January 2020 REVISED 04 April 2020 ACCEPTED 06 April 2020

\begin{abstract}
The bond strength between rebar and concrete is important for the quality performance of reinforced concrete structures. At the interface, bond strength development mainly depends on surface configuration. Different rib configuration improves the strength significantly in high yield rebars as compared to mild steel. This study examines the bond strength behavior of ordinary MS (Mild Steel) rebars, HYSD (High Yield Strength Deformed) parallel rib, and HYSD diamond rib rebars. Experimental analysis to obtain pull-out behavior of rebar in concrete was based on IS 2770 Part I - 1967: Reaffirmed 2007; Indian Standard Methods of Testing Bond in Reinforced Concrete. Importantly, the concrete of M30 grade was used and a total of nine specimens were tested. The cubes of size $150 \mathrm{~mm} \times 150 \mathrm{~mm} \times 150 \mathrm{~mm}$ were cast with centrally embedded rebar provided up to $20 \mathrm{~mm}$ from their bottom faces. Additionally, the pull-out test was conducted in $1000 \mathrm{kN}$ capacity Universal Testing Machine. The usable bond strength values were calculated from the load at $0.025 \mathrm{~mm}$ free and $0.25 \mathrm{~mm}$ loaded end slips. The results showed that the usable bond strength value of HYSD diamond rib rebars is very large compared to MS and appreciably greater than HYSD parallel rib. Moreover, the usable bond strength of HYSD diamond rib rebars is $60.06 \%$ and $35.60 \%$ greater than that of the MS rebars and HYSD parallel rib pattern rebars, respectively. The high frictional resistance developed in the bond strength test of HYSD diamond rib rebars because of the better mechanical interlocking. This was primarily due to the presence of a more frictional surface area of lugs.
\end{abstract}

KEYWORDS Reinforced Concrete; Bond Strength; MS Rebar; HYSD Rebar; Rib Configuration.

(c) The Author(s) 2020. This article is distributed under a Creative Commons Attribution-ShareAlike 4.0 International license.

\section{INTRODUCTION}

Reinforced concrete is a compound material with comparatively low tensile strength. Its ductility is enhanced by the addition of reinforcement with higher tensile strength. This is achieved using steel reinforcing rebars embedded passively in the concrete before it sets. The tensile strength of steel and the compressive strength sustain the stresses over considerable time. The combined action of concrete and reinforcing steel bar is due to the interaction between the two at the interface which makes the mutual transfer of stresses between the materials possible (Ferguson, 1966).
The interaction at the interface of two materials is commonly known as a bond and its strength is described by three factors, including chemical adhesion, friction resistance, and mechanical interlocking of bar deformation and adjoining concrete (Gan, 2000; Barbosa, 2013). The chemical adhesion is less important in magnitude and resists only small stress due to friction, whichis a mechanical interlock between irregularities of steel surface and concrete with superior magnitude happens after the adhesion breaks and some slight movement between steel and concrete occurs. Once these two bond mechanisms are lost, the tension is transferred 
by mechanical interlocking through bar deformation. Generally, the mechanism transferring forces between short concrete corbels surrounding the ribs of the bar are critical. In the plain rebars, the bond is formed by two parcels, including the chemical adhesion and frictional resistance (Abrams, 1913).

The ultimate force is proportional to the lateral area of rebar, where adhesion effect and friction occurs, and the deformed surface is present. In the deformed bar, the higher strength is due to the action of the surface ribs. Reinforcement for concrete to develop the strength of a section in tension depends on the compatibility of the two materials to act together in counteracting the external load. The reinforcing rebar needs to experience the same strain or deformation as the surrounding concrete to avoid the disruption or separation of the two materials under load.

To raise the capacity of reinforced concrete significantly, the modulus of elasticity, the ductility, and the yield or rupture strength of the reinforcement should be extremely high. The ideal rebar ought to have high strength per unit area, superior bond with surrounding concrete, high resistance to pull-out forces, and fair corrosion, and should be accessible at a reasonable cost. Until 1960, plain round mild steel straight bars were used as reinforcements in reinforced concrete (Anil, 2011).

Plain round mild steel rebars are considered suitable due to their matching bond strength corresponding to the yield ability of the rebars. To increase the bond strength of the reinforcing steel bars with high yield strength, protrusions were introduced on the surface of the straight rebars. In case the rebars have protrusions on the surface, they are termed deformed. The bond strength of deformed rebars is much larger, specifically two to three times than the plain round mild steel straight with the concrete (Hong and Park, 2012). Additionally, the conventional high yield strength deformed
(HYSD) and thermo mechanically treated (TMT) rebars are mostly used in the construction sites to offer high strength, superior bond at the interface, and high resistance against pull-out forces (Huang et al, 1996).

\section{METHODS}

\subsection{Material Properties and Mix Design}

The materials used in the experimental study include 53 grade ordinary Portland cement (OPC), $2.36 \mathrm{~mm}$ downgraded river sand as fine aggregate, $20 \mathrm{~mm}$ downgraded blue granite coarse aggregate, and portable water. The following basic material property test results were reported as shown in Table 1.

Table1: Material properties of cement, fine aggregate, and coarse aggregate

\begin{tabular}{ll}
\hline Constituent & Properties \\
\hline Cement & Specific gravity -3.12 \\
\hline Fine & Fineness modulus -3.05 \\
Aggregate & Specific gravity -2.4 \\
& Water absorption $-5.75 \%$ \\
& Confirming to zone - II \\
& Grading conforming to IS 383-1970 \\
\hline Coarse & Specific gravity -2.5 \\
Aggregate & Water absorption $-0.25 \%$ \\
& Grading conforming to IS 2386-1963 \\
\hline
\end{tabular}

The material property test results of mix design for M30 concrete were formulated for as per IS 10262: 2009 as shown in Table 2.

Table 2: Design mix proportions for $1 \mathrm{~m}^{3}$ of concrete

\begin{tabular}{llll}
\hline Cement(kg) & FA(kg) & CA(kg) & Water(Liters) \\
\hline 438 & 588.74 & 1044.22 & 197.00 \\
1 & 1.34 & 2.38 & 0.45 \\
\hline
\end{tabular}

CA: Coarse Aggregate, FA: Fine Aggregate

Each rebar of $16 \mathrm{~mm}$ diameter of mild steel of grade $\mathrm{f}_{\mathrm{y}}=250 \mathrm{MPa}$, HYSD parallel ribs, and HYSD

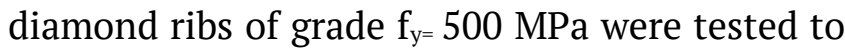
determine the corresponding bar chemical composition as shown in Table 3. Also, tension tests were conducted to check the physical property of specimens as presented in Table 4 . 
The tension test was performed for 6 samples in each category. Moreover, the chemical composition test results for each rebar category were compared with the standard values and the test results were in the optimum range.

\subsection{Experimental Program}

The pull-out test was carried out on rebars as per IS 2770 Part I - 1967 considering the modifications outlined in IS 1786 - 1985. The surface condition investigated includes Mild steel, HYSD parallel ribs, HYSD diamond ribs rebar of $16 \mathrm{~mm}$ diameter. In each category, three specimens were cast to nine, then subjected to the pull-out test, which used a universal testing machine of $1000 \mathrm{kN}$ capacity. Dial gauge with a least count of $0.001 \mathrm{~mm}$ was used to measure free end (FE) and loaded end (LE) slips. Furthermore, the load was applied at a constant rate without shock and the verses slip behaviors were monitored beyond the required slip levels for calculating the ultimate load carried by each specimen before failure. Concrete cubes of size $150 \mathrm{~mm} \times 150 \mathrm{~mm} \times 150 \mathrm{~mm}$ were cast with centrally embedded rebar of up to $20 \mathrm{~mm}$ from the bottom face. The rebar was extended over the top face for a sufficient length of $420 \mathrm{~mm}$ to facilitate its gripping in the testing machine. Helical reinforcement of $6 \mathrm{~mm}$ diameter mild steel with a pitch of $25 \mathrm{~mm}$ for a diameter of 110 $\mathrm{mm}$ was kept inside the mould for the confinement of surrounding concrete. A suitable 4-legged mild steel clamp was provided at the top after casting to maintain the eccentricity of the bar. The experimental arrangement for casting and testing of specimens and various categories of rebars are presented in Figure 1 and 2 , respectively.

Table 3: Chemical composition test results

\begin{tabular}{llll}
\hline Characteristic Test & MS rebar Results & $\begin{array}{l}\text { HYSD rebar } \\
\text { Results(Parallel ribs) }\end{array}$ & $\begin{array}{l}\text { HYSD rebar Results(Diamond } \\
\text { ribs) }\end{array}$ \\
\hline Carbon, (\%) & 0.284 & 0.203 & 0.222 \\
Manganese, (\%) & 0.553 & 0.696 & 0.567 \\
Silicon, (\%) & 0.157 & 0.208 & 0.104 \\
Sulphur, (\%) & 0.028 & 0.024 & 0.024 \\
Phosphorous, (\%) & 0.036 & 0.033 & 0.032 \\
Chromium, (\%) & 0.190 & 0.092 & 0.186 \\
Nickel, (\%) & 0.099 & 0.068 & 0.069 \\
Molybdenum, (\%) & 0.017 & 0.013 & 0.016 \\
\hline
\end{tabular}

Table 4: Tensile test results of different categories of rebars

\begin{tabular}{lllll}
\hline \multirow{2}{*}{ Type } & \multicolumn{3}{c}{ Properties } \\
\cline { 2 - 5 } & $\begin{array}{l}\text { Yield Strength } \\
(\mathrm{MPa})\end{array}$ & $\begin{array}{l}\text { Ultimate Strength } \\
(\mathrm{MPa})\end{array}$ & $\begin{array}{l}\text { Percentage } \\
\text { Elongation }\end{array}$ & $\begin{array}{l}\text { Percentage } \\
\text { reduction in area }\end{array}$ \\
\hline MS Plain rebars & 466.72 & 583.40 & 27.50 & 53.24 \\
HYSD Parallel ribs & 498.36 & 622.43 & 22.50 & 55.45 \\
HYSD Diamond ribs & 547.38 & 684.91 & 26.20 & 54.90 \\
\hline
\end{tabular}



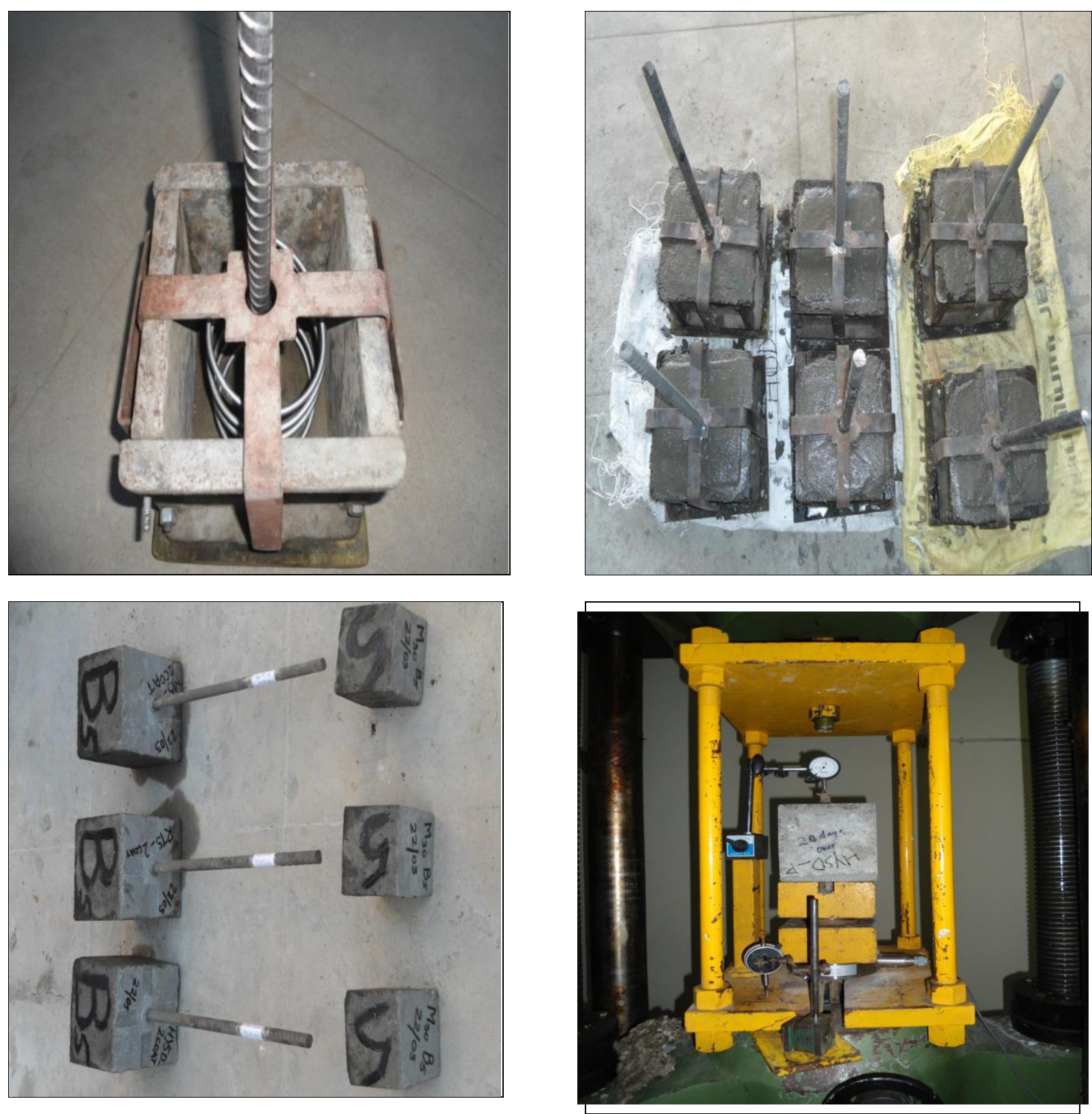

Figure 1. Arrangement for casting and testing of pull-out specimens

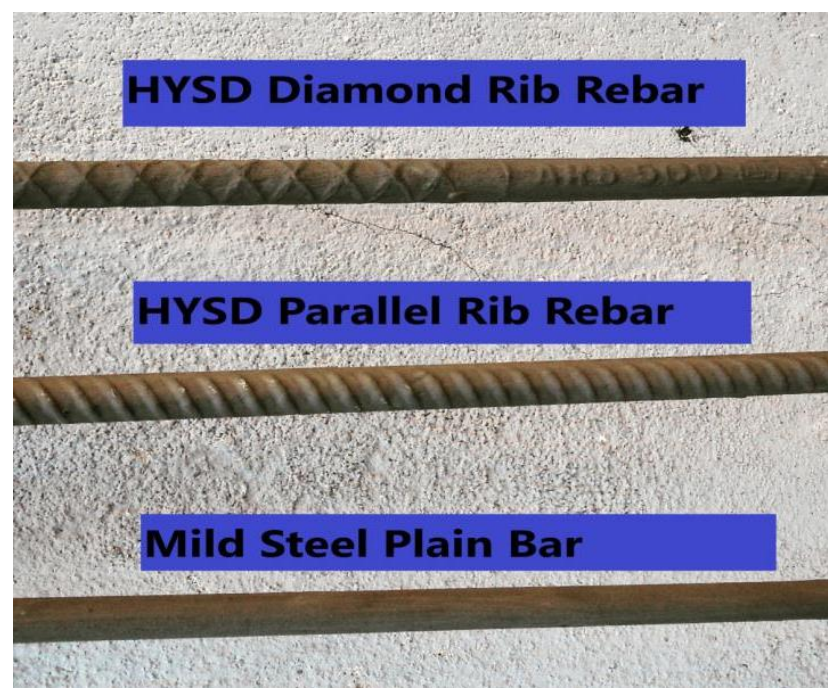

Figure 2: Different rib configurations used in the study 196
The rebar bonded length in concrete was restricted to 5 times its diameter and provided from the bottom of the cube mould. To avoid the bond near the loaded end, a plastic sleeve was used in the remaining length. Once the curing period was complete, a neat gypsum plaster capping was done on the top face of the specimen to facilitate proper seating on the testing facility. The specimens were tested after 28 days. 


\section{RESULTS AND DISCUSSION}

The test results were analyzed based on IS 27701967 by observing the load at $0.25 \mathrm{~mm}$ loaded end (LE) and $0.025 \mathrm{~mm}$ free end (FE) slips, as well as the ultimate failure load. The minimum corresponding to the $0.025 \mathrm{~mm}$ free end and 0.25 $\mathrm{mm}$ loaded end slips are considered for calculating the usable bond strength. However, each bar in all three categories showed uneven variations in load value due to abrupt change in readings in dial gauge on load increment. Therefore, slip reading at a particular UTM load value couldn't be precisely taken. The highest load value in each specimen was used to predict usable bond strength and to understand the load-slip behavior best.

Table 5 shows the observation on the pull-out test for all the 9 specimens. In the mild steel category, the load values at $0.025 \mathrm{~mm} \mathrm{FE}$ and $0.25 \mathrm{~mm}$ LE slip values for specimen 1 and 3 are almost similar. However, the corresponding load values for specimen 2 are less, hence not considered. In HYSD parallel rib category, load values at $0.025 \mathrm{~mm}$ FE slip for specimen 3 were the highest, specifically $29.5 \mathrm{kN}$ than the other two. In HYSD diamond ribs, specimen 3 has the highest load values at $0.025 \mathrm{~mm}$ FE slip, precisely $40 \mathrm{kN}$. This is highest compared to the mild steel bar and HYSD parallel ribs.

Table 6 shows usable bond strength and its corresponding ultimate load beyond which the dial gauge didn't show any increment in reading for the optimum among 3 specimens in each category. In mild steel rebar, the usable bond strength is $6.21 \mathrm{MPa}$ while the ultimate load before failure is $29 \mathrm{kN}$. In HYSD parallel ribs rebar, the usable bond strength is $7.33 \mathrm{MPa}$ while its corresponding ultimate load is $110.05 \mathrm{kN}$. In HYSD diamond ribs rebar, the usable bond strength is greater than both mild steel and HYSD parallel ribs rebar. It is9.94 MPa while its ultimate load is $108 \mathrm{kN}$.

Table 5: Observations on pull-out test

\begin{tabular}{|c|c|c|c|c|c|}
\hline \multirow{2}{*}{\multicolumn{2}{|c|}{ Type of specimens }} & \multicolumn{2}{|l|}{ Load $(\mathrm{kN})$} & \multirow{2}{*}{$\begin{array}{l}\text { Usable Bond } \\
\text { strength (MPa) }\end{array}$} & \multirow{2}{*}{ Variation (\%) } \\
\hline & & 0.025 mm FE slip & $0.025 \mathrm{~mm}$ LE slip & & \\
\hline \multirow{3}{*}{ Mild steel } & $\mathrm{S} 1$ & 25.83 & 27.25 & 6.77 & - \\
\hline & $\mathrm{S} 2$ & 13.50 & 15.45 & 3.84 & -43.27 \\
\hline & S3 & 25.00 & 25.00 & 6.21 & -8.27 \\
\hline \multirow{3}{*}{$\begin{array}{l}\text { HSYD } \\
\text { parallel ribs }\end{array}$} & S4 & 14.50 & 11.50 & 3.60 & -46.82 \\
\hline & S5 & 17.50 & 6.25 & 4.35 & -35.74 \\
\hline & S6 & 29.50 & 9.25 & 7.33 & +8.27 \\
\hline \multirow{3}{*}{$\begin{array}{l}\text { HYSD } \\
\text { diamond ribs }\end{array}$} & S7 & 20.79 & 19.90 & 5.17 & -23.63 \\
\hline & S8 & 22.00 & 2.79 & 5.47 & -19.20 \\
\hline & S9 & 40.00 & 21.50 & 9.94 & +46.82 \\
\hline
\end{tabular}

S: Specimen

Table 6: Usable bond strength of mild steel, HYSD parallel rib, and HYSD diamond rib rebars

\begin{tabular}{|c|c|c|c|c|c|}
\hline \multirow[b]{2}{*}{ Type of specimens } & \multicolumn{2}{|l|}{ Load $(\mathrm{kN})$} & \multirow{2}{*}{$\begin{array}{l}\text { Ultimate } \\
\text { Load } \\
(\mathrm{kN})\end{array}$} & \multirow{2}{*}{$\begin{array}{l}\text { Usable Bond } \\
\text { strength } \\
(\mathrm{MPa})\end{array}$} & \multirow{2}{*}{$\begin{array}{l}\text { Variation } \\
(\%)\end{array}$} \\
\hline & $\begin{array}{l}0.025 \mathrm{~mm} \mathrm{FE} \\
\text { slip }\end{array}$ & $\begin{array}{l}0.025 \mathrm{~mm} \\
\text { LE slip }\end{array}$ & & & \\
\hline MS rebar & 25 & 25 & 29 & 6.21 & - \\
\hline HYSD parallel rib rebar & 29.5 & 9.25 & 110 & 7.33 & +18.03 \\
\hline HYSD diamond rib rebar & 40 & 21.5 & 108 & 9.94 & +60.06 \\
\hline
\end{tabular}


Figure 3 shows the load-slip behavior of mild steel rebars. The load-slip behavior of specimen 2 reveals less resistance at $0.025 \mathrm{~mm}$ FE slip level against a load. It is followed by a gradual increase in slip and fails earlier compared to the other two specimens. Specimens 1 and 3 showed some slip resistance at FE in the beginning with a gradual rise in the slip at increased load values. The load-slip behavior in the loaded end was different in specimen 2 , which showed resistance at the initial stage. Moreover, there was a gradual increase in slip due to the rise in the load. Specimens 1 and 3 exhibit the same kind of behavior as in FE. However, specimen 3 showed optimum behavior both at FE and LE with an ultimate load of $29 \mathrm{kN}$.
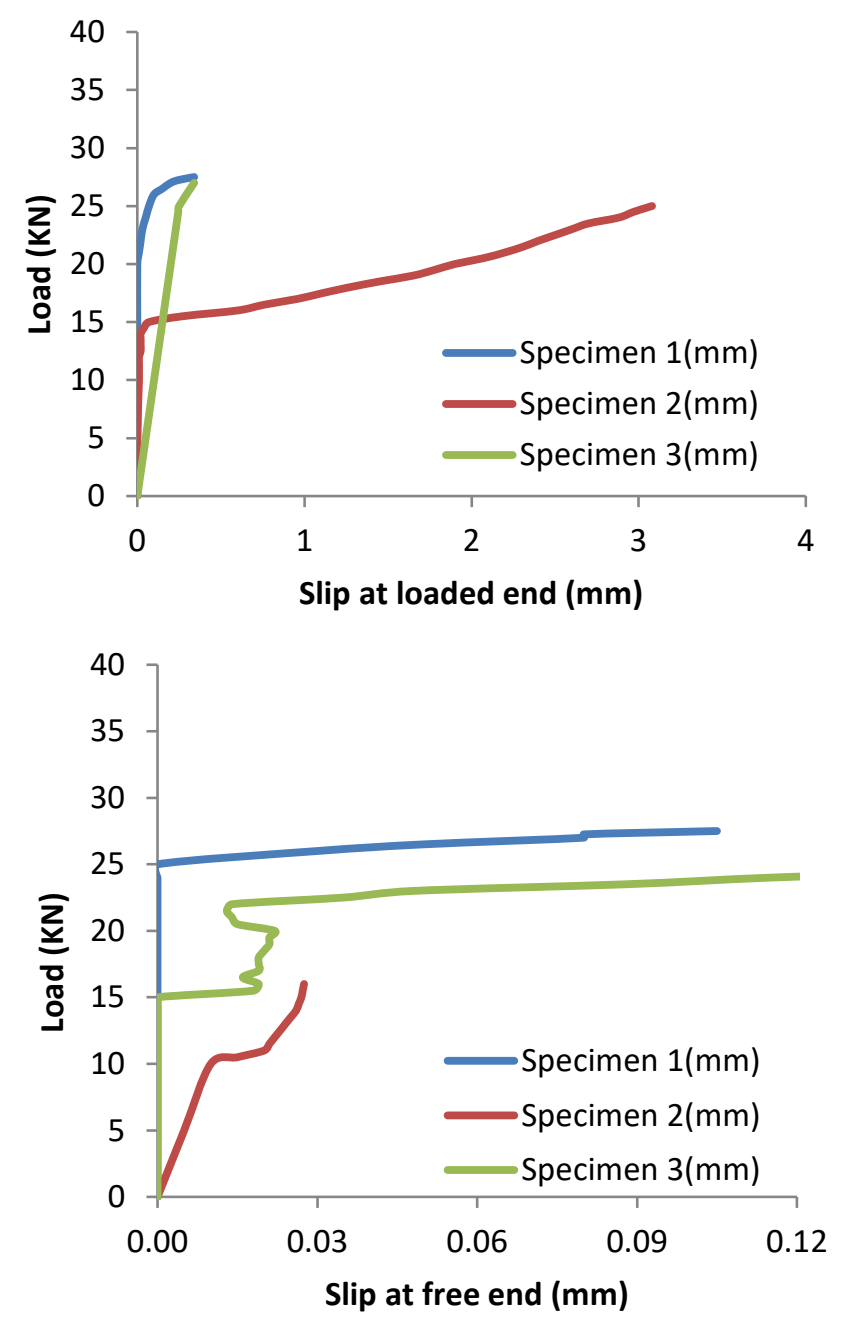

Figure 3. Load versus slip behavior of MS rebars

Figure 4 shows the load-slip behavior of HYSD parallel rib rebars. At FE reveals, specimens 1 and 2 show less resistance at $0.025 \mathrm{~mm}$ FE slip level against a load. This is followed by a gradual increase in the slip values upon further loading. Specimen 3 at FE shows the load values at $0.025 \mathrm{~mm}$ slip level is appreciably higher than those of ordinary mild steel. Also, the behavior at LE for HYSD parallel rib rebars are entirely different.
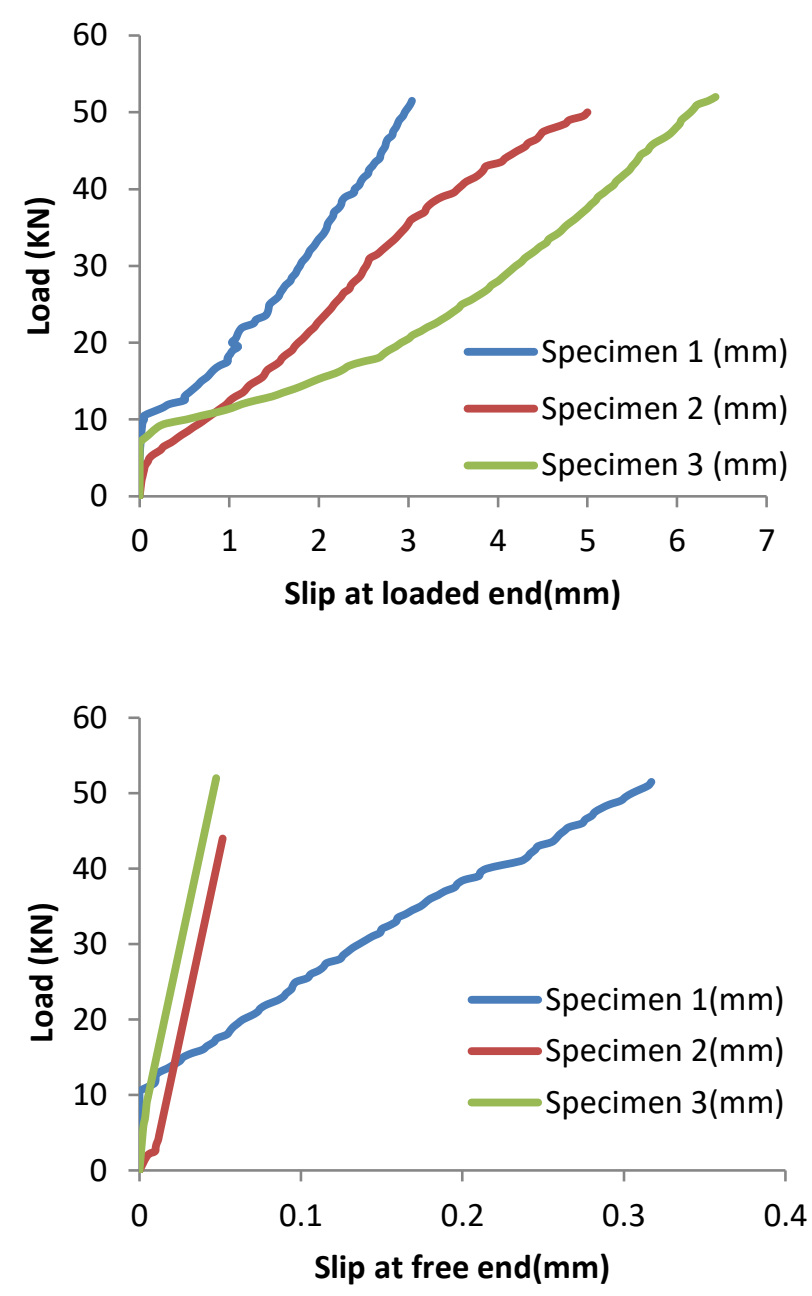

Figure 4. Load versus slip behavior of HYSD parallel rib rebars

Figure 5 shows the load-slip behavior of HYSD diamond rib rebars. At FE, specimen 1 and 2 are in line with each other. In LE, specimen 1 and specimen 3 exhibit the same kind of behavior. In contrast, specimen 2 offers less initial resistance at LE and there is increased slip exhibited with a gradual increase in load. Specimen 3 exhibits an appreciable slip resistance with load increment withstanding an ultimate load of $108 \mathrm{kN}$. 

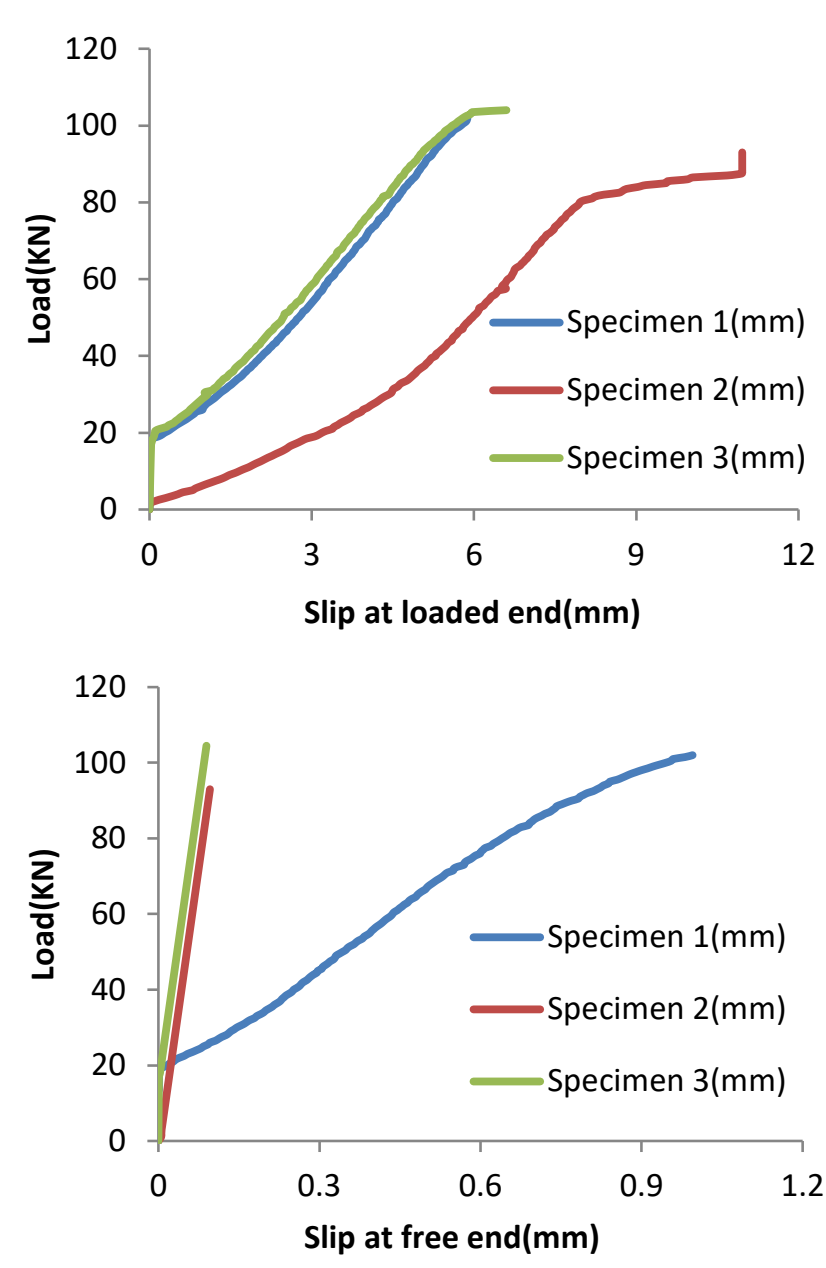

Figure 5. Load versus slip behavior of HYSD diamond rib rebars

When the three categories of rebars were tested and subjected to the ultimate load, no crack pattern was observed in the surrounding concrete. However, mild steel rebars came out of concrete, leaving a hole in the cube. In HYSD parallel and diamond rib rebars, a little gliding was observed at the contact surface of concrete and at the time of failure. Figure 6 shows the failure of parallel and diamond rib rebar in a concrete cube.

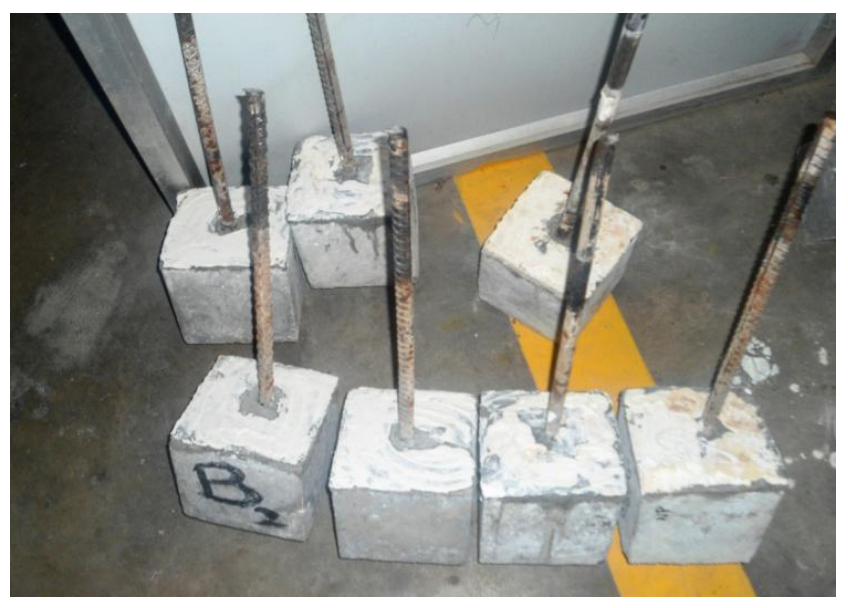

Figure 6. HYSD parallel and diamond rib rebar failure

\section{CONCLUSIONS}

Usable bond strength values of mild steel rebar are nearer to the ultimate loads. This means they cannot withstand more load once the slip occurs. Specimen 3 showed optimum load-slip behavior both at FE and LE with an ultimate load of $29 \mathrm{kN}$. The usable bond strength values of HYSD parallel rib rebars are higher than mild steel, about $18.03 \%$ with the greater ultimate load. This is due to the existence of parallel surface protrusions or lugs, which offer better mechanical interlocking. The ultimate load resisted by HYSD diamond rib rebars before failure is very large compared to usable bond values. Additionally, the value of the ultimate load is comparatively higher than MS and HYSD with parallel ribs. In contrast, the diamond rebars have a rib pattern which ensures better mechanical interlocking. This is attributed to the presence of a more frictional surface area of lugs which produces additional resistance. Usable bond strength is $60.06 \%$ and $35.60 \%$ greater than MS rebars and HYSD with parallel rib pattern, respectively. 


\section{DISCLAIMER}

The authors declare no conflict of interest.

\section{ACKNOWLEDGEMENTS}

The authors are grateful for the critical comments of anonymous reviewers and the Editor, which helped in improving the quality of this paper.

\section{REFERENCES}

Abrams, D. A., 1913.Tests of bond between concrete and steel. University of Illinois at Urbana Champaign, College of Engineering. Engineering Experiment Station.

Anil K. K., 2011," A Rebar Durable Concrete Construction”, The Master Builder, pp.224-236, July, 2011.

Barbosa, M. T. G., and Filho, S. S.,2013. Investigation of bond stress in pull out specimens with high strength concrete. Journal of Researches in Engineering Civil and Structural Engineering13(3), pp. 55-64

Ferguson, P. M.,1966. Bond stress the state of the art.Journal of the American Concrete Institute63(1), pp.1161-1190.
Gan, Y., 2000. Bond Stress and Slip Modeling In Nonlinear Finite Element Analysis of Reinforced Concrete Structures. Toronto: Master Thesis Report, University of Toronto.

Hong, S. and Park, S. K.,2012. Uniaxial bond stress-slip relationship of reinforcing bars in concrete. Advances in Materials Science and Engineering 2012.

Huang, Z., Engström, B., and Magnusson, J.,1996. Experimental and analytical studies of the bond behaviour of deformed bars in high strength concrete. In 4th International Symposium on the Utilization of High Strength/High Performance Concrete (Vol. 3).

Indian Standard Institution, 1985. IS 1786: 1985,. Indian Standard Specification for High Strength Deformed Steel Bars and Wires for Concrete Reinforcement. New Delhi: Bureau Standard of India.

Indian standard Institution, 1967. IS 2770:1967 Part 1,"Methods of Testing Bond in Reinforced Concrete Pull-out Test", Part 1.New Delhi: Bureau Standard of India.

Indian Standard Institution, 2009. IS: 10262., 2009. Concrete Mix Proportioning-Guidelines. New Delhi: Bureau Standard of India 